\title{
Social Welfare Maximization by Optimal Locating and Sizing of TCSC for Congestion Management in Deregulated Power Markets
}

\author{
Seyed Mohammad Hosseini Nabavi ${ }^{(1)}$, Nazanin Alsadat Hosseinipoor ${ }^{(2)}$, Somayeh Hajforoosh ${ }^{(3)}$ \\ (1) (2) (3) Islamic Azad University, Tabriz Branch, Tabriz, Iran
}

\begin{abstract}
Series FACTS devices such as TCSC, with its ability to directly control the power flow can be very effective to improve the operation of transmission network. In this paper, a corrective solution for congestion management by using TCSC has been reviewed. A genetic algorithm for finding the optimal location and size of this device is proposed for congestion management with the aim of increasing social welfare while cost of TCSC was incorporated. The simulation results were successfully tested on the IEEE 30-bus system. Analyzing the results with and without TCSC confirms that this device is an appropriate for a long time congestion management.
\end{abstract}

Index Terms-- congestion management; deregulated power market; genetic algorithm; optimal power flow; social welfare; TCSC;

\section{INTRODUCTION}

The restructuring in electric power industries from the last two decades was introduced with privatization in their sectors to improve their efficiency [1]. However, as the deregulation progresses among power utilities, the utility operators face new problems and challenges [2]. Since the generation investment decision currently is in the hand of private entity, obviously there is lack of coordination between the generation and transmission investments as well. Moreover, the provision of bilateral transaction, that allows GENCO and DISCO pairs to negotiate power transactions, has lead to uncertainty in the amount and direction of power flows. Evidently, the overall consequence of this issue is the congestion in transmission network. The issue of transmission congestion is more pronounced in deregulated and competitive markets and it needs a special treatment [3]. In this environment, independent system operator (ISO) has to relieve the congestion, so that the system is maintained in secure state. To relieve the congestion ISO can use mainly two types of techniques which are as follows [4-5]:

A. Cost free means:

- Out-ageing of congested lines

- Operation of transformer taps/phase shifters

- Operation of FACTS devices particularly series devices

\section{B. Non-Cost free means:}

- Re-dispatching the generation amounts. By using this method, some generators back down while others increase their output. The effect of re-dispatching is that generators no longer operate at equal incremental costs.
- Curtailment of loads and the exercise of load interruption options.

Among the above two main techniques cost free means do have advantages such as not touching economical matters, so GENCO and DISCO will not be involved.

Hence, FACTS devices are utilized as one of such technology which can reduce the transmission congestion and leads to better using of the existing grid infrastructure. Besides, using FACTS devices gives more opportunity to ISO [1]. Various issues associated with the usage of FACTS devices are their optimal location and appropriate size, setting, cost, and modeling.

This paper deals with the optimal locating and sizing of a TCSC, for congestion management in competitive power markets. Up to now, the sensitivity factor methods are generally used to find the best location to enhance the static performance of the system [6]. However, there are some disadvantages for this method such that it may not capture the non-linearity associated with the power system.

Genetic algorithm as an evolutionary method can be applied as a good solution for optimization of OPF problem by incorporating FACTS devices and consequently considering the non-linearity of the system into account. However, various optimization techniques are available to OPF problem [7].

In this paper, the TCSC model is discussed in section II. Section III describes the proposed method and formulation of OPF. In section $\mathrm{IV}$, results and discussion are presented and finally, conclusions are given in section $\mathrm{V}$.

\section{TCSC MODELING}

For static application like congestion management FACTS devices can be modeled as Power Injection Model [1]. The injection model describes the FACTS devices as a device that injects a certain amount of active and reactive power to a node, so that the FACTS devices are presented as PQ elements.

During steady state operation, TCSC can be considered as an additional reactance $-j x_{c}$. The value of $x_{c}$ is adjusted according to control scheme specified. Fig. 1(a) shows a model of transmission line with one TCSC which is connected between bus-i and bus-j. The line flow change is due to series capacitance which is represented as line without series capacitance with power injected at the receiving and sending ends of the line as shown in Fig. 1(b).

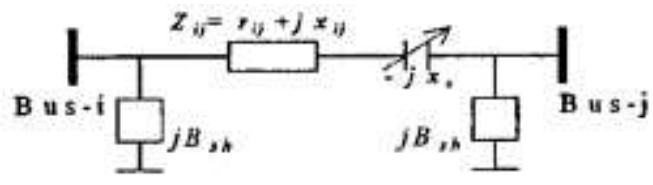

Fig.1 (a) TCSC model 


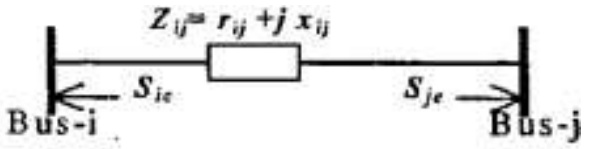

Fig.1 (b) Injection model of TCSC

The real power injections at bus- $i\left(P_{i c}\right)$ and bus- $j\left(P_{j c}\right)$ are given by [8]:

$$
\begin{aligned}
& P_{i c}=V_{i}^{2} \Delta G_{i j}-V_{i} V_{j}\left[\Delta G_{i j} \cos \delta_{i j}+\Delta B_{i j} \sin \delta_{i j}\right] \\
& P_{j c}=V_{j}^{2} \Delta G_{i j}-V_{i} V_{j}\left[\Delta G_{i j} \cos \delta_{i j}-\Delta B_{i j} \sin \delta_{i j}\right]
\end{aligned}
$$

Similarly, the reactive power injections at bus- $i\left(Q_{i c}\right)$ and bus$j\left(Q_{j c}\right)$ can be expressed as:

$$
\begin{aligned}
& Q_{i c}=-V_{i}^{2} \Delta B_{i j}-V_{i} V_{j}\left[\Delta G_{i j} \sin \delta_{i j}-\Delta B_{i j} \cos \delta_{i j}\right] \\
& Q_{j c}=-V_{j}^{2} \Delta B_{i j}+V_{i} V_{j}\left[\Delta G_{i j} \sin \delta_{i j}+\Delta B_{i j} \cos \delta_{i j}\right]
\end{aligned}
$$

where:

$$
\begin{aligned}
\Delta G_{i j} & =\frac{x_{c} r_{i j}\left(x_{c}-2 x_{i j}\right)}{\left(r_{i j}^{2}+x_{i j}^{2}\right)\left(r_{i j}^{2}+\left(x_{i j}-x_{c}\right)^{2}\right)}, \\
\Delta B_{i j}= & \frac{-x_{c}\left(r_{i j}^{2}-x_{i j}^{2}+x_{c} x_{i j}\right)}{\left(r_{i j}^{2}+x_{i j}^{2}\right)\left(r_{i j}^{2}+\left(x_{i j}-x_{c}\right)^{2}\right)}
\end{aligned}
$$

This model of TCSC is used to properly modify the parameters of transmission lines with TCSC for optimal power flow algorithms in the following studies [8-9].

Cost of TCSC is represented in the form of a linear equation as [8]:

$C_{f}=c x_{c} \frac{S_{\max }^{2}}{S_{B}}$

c is the cost coefficient of TCSC (\$/MVA-year); in this study $\mathrm{c}=22,000$ \$/MVA-year is adopted [8]; Smax is the thermal limits of line where the FACTS device is placed (MVA); SB is the base power (MVA); $\mathrm{xc}$ is the series capacitive reactance (p.u.).

The formulation allows the capital cost of TCSC to vary with the TCSC capacity (MVA). Thermal limit inclusion in the problem formulation helps ISO to satisfy the thermal limit of the transmission line when a TCSC is added to that line.

\section{PROPOSED METHOD}

\section{A. Genetic algorithm}

Genetic algorithm is a general optimization purpose algorithm, based on the mechanism of natural selection and genetics. It requires the evaluation function so called fitness function (FF) to assign a quality value to every solution produced. The process starts with assuming an initial random population produced and evaluated. Genetic evaluation takes place by means if three basic genetic operators:

- Parent Selection: It is done by selecting two chromosomes from the parent population based on their fitness value. The selection rule used in this paper is the roulette-wheel selection.

- Crossover: It is an important operator for the GA. By using this operator, two parents will get combined to form a new chromosome that inherits segments or information stored in parent chromosomes. Until now, many crossover schemes have been proposed such as single point, multipoint, or uniform. In this paper a heuristic crossover has been used. In this kind, produced offspring is near to the parent with better fitness function as expressed by:

$O=P_{2}+R\left(P_{1}-P_{2}\right)$

where, P1, P2 are parents with the better fitness function, $\mathrm{O}$ is the new chromosome and $\mathrm{R}$ is the factor of nearness to the parent - assumed 1.2

- Mutation: this operator is responsible for the injection of new information. With a small probability, random bits of the offspring chromosomes flip from 0 to 1 and vice versa and give new characteristics that do not exist in the parent's population, although in this paper it is done in real mode of each variable with using normal probability distribution for producing random integer in the valid limit of variable. The FF evaluation and genetic evaluation take part in an iterative procedure, which ends when a maximum number of generation, are reached.

\section{B. Problem formulation}

OPF tool has been used normally in a pool base deregulated power markets to calculate generation dispatch and load schedules, and to manage congestion in the system. The generally accepted objective function in this environment is the maximization of social welfare. In this paper, the cost of FACTS devices is included to the social welfare maximization problem which can be expressed as:

$$
\min _{P_{G}}\left(\sum_{i=1}^{N_{G}} C_{G i} P_{G}-\sum_{j=1}^{N_{D}} B_{D j} P_{D}+\operatorname{Cost}(F A C T S)\right)
$$

where NG and ND are the number of generators and loads respectively, $C_{G i}\left(P_{G}\right)$ is the bid curve of ith generator, and $B_{D j}\left(P_{D}\right)$ is the benefit curve for the jth demand. In this study, the generation cost functions and benefit functions are assumed to be quadratic form. The selected cost and benefit coefficients are presented in Table A.1.

The power balance equations in bus $\mathrm{i}$ and bus $\mathrm{j}$ are given by:

$$
\begin{array}{lr}
P_{i} \theta, V-P_{G i}+P_{D i}=0 & \text { for } i=1, \ldots, N_{G} \\
Q_{i} \theta, V-Q_{G i}+Q_{D i}=0 & \text { for } i=1, \ldots, N_{G}
\end{array}
$$

If TCSC is located in line between bus-i and bus-j, the power balance equations in bus $\mathrm{i}$ and bus $\mathrm{j}$ will change as followed:

$$
\begin{aligned}
& P_{i} \bullet, V=P_{G i}+P_{D i}+P_{i}^{F}=0 \\
& Q_{i} \bullet, V=Q_{G i}+Q_{D i}+Q_{i}^{F}=0 \\
& P_{j} \bullet, V=P_{G j}+P_{D j}+P_{j}^{F}=0 \\
& Q_{j} \otimes, V=Q_{G j}+Q_{D j}+Q_{j}^{F}=0
\end{aligned}
$$

The equality and non-equality constrains are assumed as followed: Power generation limit: the limits on the maximum and minimum output of the generators are incorporated as:

$$
\begin{array}{ll}
P_{G i}^{\min } \leq P_{G i} \leq P_{G i}^{\max } & \text { for } i=1, \ldots, N_{G} \\
Q_{G i}^{\min } \leq Q_{G i} \leq Q_{G i}^{\max } & \text { for } i=1, \ldots, N_{G}
\end{array}
$$

Line flow limit: the limit on the MVA flow on a transmission line incorporated as:

$$
\mid S_{i j} \boldsymbol{Q}, V\left\lceil\leq S_{i j}^{\max }\right.
$$


Bus Voltage limit: Voltage limit at each bus is expressed as:

$V_{i}^{\mathrm{min}} \leq V_{i} \leq V_{i}^{\mathrm{maz}}$

TCSC reactance limit: after including TCSC, the inequality constraints will include the limits of this device, which means the maximum and minimum values of equivalent reactance (xc).

$x_{c}^{\min } \leq x_{c} \leq x_{c}^{\max }$

\section{Proposed algorithm}

A detailed step by step procedure for the proposed GA based social welfare maximization by incorporating all the constraint in the objective function is expressed as follows which is expressed in fig.2.

Step 1- Prepare a system data base (generations, loads, transmission lines, cost and benefit coefficients).

Step 2- Assume GA parameters (population size (pop-size), maximum number of generators (gen-max), crossover rate (cr), and mutation rate $(\mathrm{mr}))$.

Step 3- Generate chromosomes randomly which include power generation schedule, Location and size of TCSC.

- The values of power generation corresponding to the ith generator may be expressed by the following: $P_{g i}=\lambda \times P_{g \max i} \quad 0 \leq \lambda \leq 1$

- The location of FACTS devices is described by: FACTS $_{\text {Location }}=I N T[$ no. lines $\times \lambda]+1, \quad 0 \leq \lambda \leq 1$

Where no. lines is the number of transmission lines.

- The size of FACTS devices with respect to location of placement of the device can be described by: TCSC $_{\text {Size }}=\lambda \times X_{\text {FACTS }_{\text {Location }}}, 0 \leq \lambda \leq 0.7$

Step 4- Run the power flow.

Step 5- Check the equality and non-equality constraints of the system as described before.

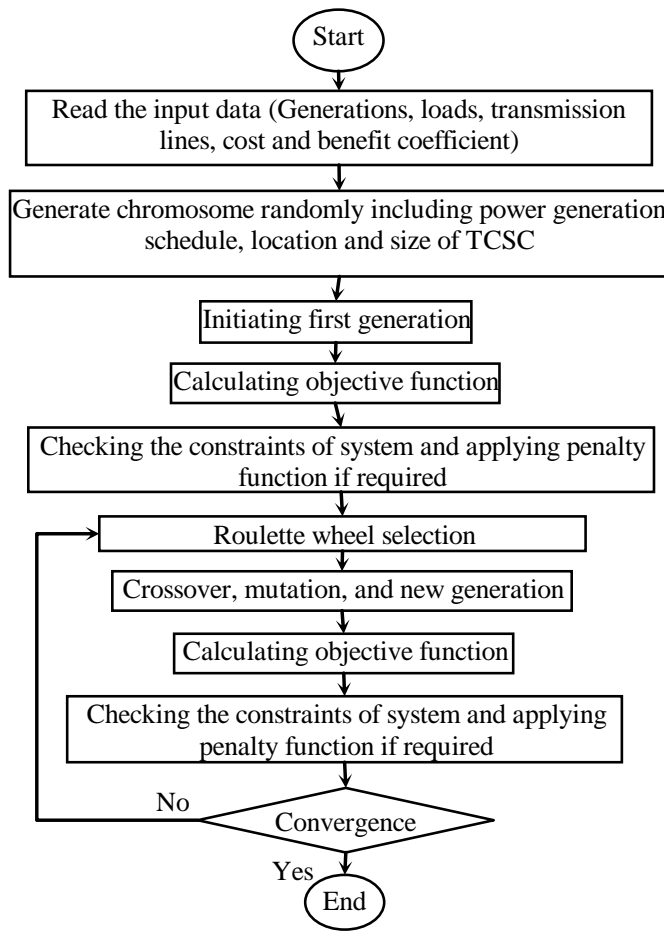

International Journal of Computer Applications (0975 - 8887)

Volume 6-No.6, September 2010

Fig. 2.Optimization objective function process

Step 6- If the bus voltage or line flows violated then penalty functions will be applied to each chromosome, as shown in Fig. 3(a) and 3(b).
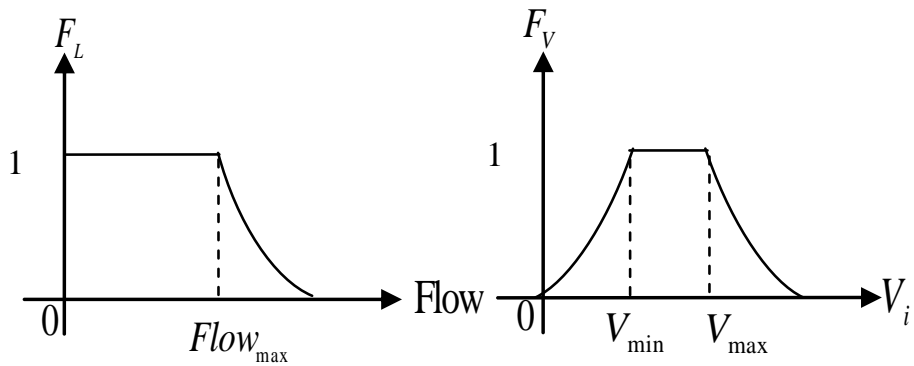

Fig. 3 Penalty functions: (a) $\mathrm{F}_{\text {Line Flow-Limit }}$ (b) $\mathrm{F}_{\text {Bus-Voltage -Limit }}$

Step 7- If pop-vn less than or equal to pop-size go to step 3; otherwise go to next step.

Step 8-Calculate and store the value of objective function (maximizing social welfare or minimizing cost of generation with considering cost of FACTS devices) corresponding to each valid generation pattern of a chromosome.

Step 9- Find and store Swami among all valid chromosomes and corresponding generation pattern.

Step 10- Set generation count gen-count $=1$.

Step 11- The fitness of each chromosome is defined as:

$f t_{i}=\frac{A}{\cos t_{i}} \quad, \quad i=1$ to pop - size

where A is a very large constant; Costi is the cost corresponding to the $i^{\text {th }}$ chromosome; $f t_{i}$ is the fitness value of function for $i^{\text {th }}$ chromosome.

Step 12- Construct a roulette wheel for selection process, as follows:

- Calculate the total fitness value: $F t=\sum_{i=1}^{p o p-s i z e} f t_{i}$

- Calculate the probability of selection using the formula: $p_{i}=\frac{f t_{i}}{F t} \quad i=1, \ldots$, pop - size

- Determine cumulative probabilities for each chromosome: $q_{i}=\sum_{j=1}^{i} p_{j} \quad, \quad i=1$ to pop - size

- Generate random number $\mathrm{r}_{\mathrm{i}}$ (for $\mathrm{i}=1$, pop-size) in the range $\{0,1\}$.

- If $r_{i}<q_{i}$ then select the first chromosome; otherwise select the $m^{\text {th }}$ chromosome such that: $q_{m-1}<r_{i}<q_{m}$

Step 13- Apply the recombination operator, crossover to the individuals in the selected population as follows:

- Generate random number $r_{i}$ (for $\mathrm{i}=1$, pop-size) in the range $\{0,1\}$

- If $r_{i}<c r$ for $\mathrm{i}=1$ to pop-size, select $i^{\text {th }}$ chromosome for crossover.

- If the numbers of selected chromosomes are odd, add or remove one selected chromosome randomly. 
- For each pair of coupled chromosomes, generate a random integer number posi in the [1, k-1]. The number posi indicate the position of crossing point.

Step 14- Run the power flow, then determine the generation patterns $\left(P_{g i}\right)$, voltage magnitudes and phase angles at all buses.

Also calculate power flow in each transmission line of the system.

Step 15- Check the equality and non-equality constraints of the system.

Step 16- If all the constraints in step 15 are satisfied the chromosome becomes valid otherwise it becomes invalid and hence rejected.

Step 17- Find the maximum social welfare among all valid chromosomes, if it is better than $S w_{a m i}$, store this cost in variable $S w_{\text {ami }}$ and also store correspondingly generation pattern.

Step 18- Add to the list of valid chromosomes, the best parents. So that total list contains pop-size valid chromosome.

Step 19- If the mutation has been performed in the current generation; go to step 21; otherwise go to next step.

Step 20- The operator mutation is following:

- Generate random number $r$ in the range $\{0,1\}$.

- If $r<m r$, apply mutation.

- For checking system constraints and for determining Cmin, go to step 14 .

Step 21- Increment the generation count gen-count by 1 . If gencount < gen-max, go to step 13. Otherwise print the optimal solution among all population groups.

\section{RESUlts AND DISCUSSION}

The proposed methodology has been implemented on IEEE 30 bus system which is shown in Fig. 4 [10] to demonstrate the robustness of proposed method. The network and load data for this system are taken from [10]. Line limits for IEEE 30-bus system are taken from [10]. The results obtained have been found satisfactory.

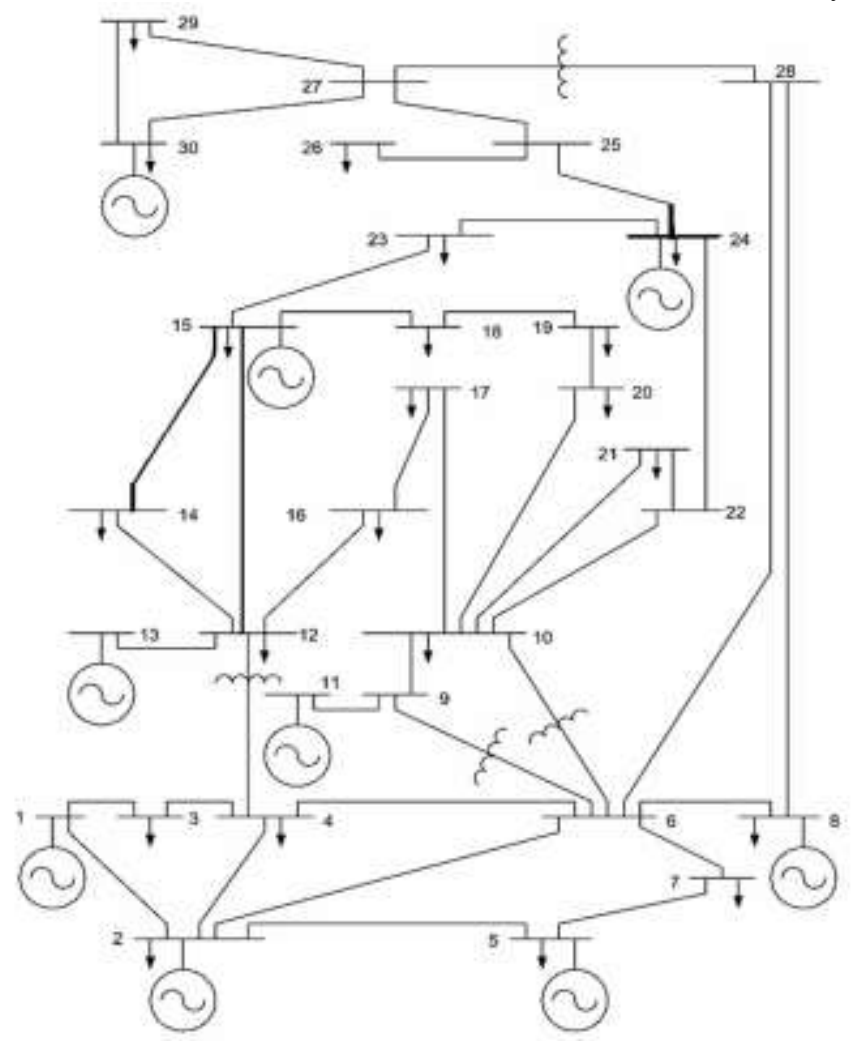

Fig. 4. IEEE 30-bus system [10]
In this system maximum total active load is $283.4 \mathrm{MW}$ and maximum total generation is $470 \mathrm{MW}$. The used genetic parameters for optimal locating and size one unit TCSC is presented in Table I.

The obtained results without using TCSC for maximizing the social welfare are presented in table II. In this case, the maximum social welfare is $7854 \$ / \mathrm{h}$. Also, the generation cost is $6370.11 \$ / \mathrm{h}$.

The proposed algorithm is utilized to obtain the generation schedule, location and size of TCSC with objective function of maximizing social welfare. By using one unit TCSC which is optimally placed on line 1-2, the congestion is relieved. In this case all generators operate without forcing generator to operate out of their equilibrium incremental costs. In the proposed GA algorithm, each chromosome has 32 genes. Nine first genes correspond to generation schedule, 21 for loads and one gene shows FACTS location and has an integer value in the range of $\{1,41\}$ since there are 41 lines that TCSC can placed on and the last one correspond to TCSC size, a value between $\left(x_{T C S C}^{\min }, x_{T C S C}^{\max }\right)$.

By implementing the proposed GA to the objective function which is presented by equation 6 , the social welfare increases form $7854.920 \$ / \mathrm{h}$ to 8000.50 . Moreover, the generation cost is decreased to 6224.530, and the benefit function is not changed. The detail results by optimal setting TCSC parameters are presented in Table III.

TABLE I. GA PARAMETERS

\begin{tabular}{|c|c|}
\hline Population size & 100 \\
\hline Crossover rate & 0.85 \\
\hline Mutation rate & 0.05 \\
\hline Maximum iteration & 500 \\
\hline
\end{tabular}

TABLE II. OPTIMIZATION PROBLEM RESULT WITHOUT TCSC

\begin{tabular}{|c|c|c|c|}
\hline $\begin{array}{l}\text { Gen } \\
\text { No. }\end{array}$ & $\begin{array}{c}\text { Generation schedule } \\
\text { (MW) }\end{array}$ & $\begin{array}{l}\text { Social } \\
\text { welfare }\end{array}$ & $\begin{array}{c}\text { Total Generation cost } \\
(\$ / \mathbf{h})\end{array}$ \\
\hline G1 & 10 & \multirow{9}{*}{7854.920} & \multirow{9}{*}{6370.110} \\
\hline G2 & 5 & & \\
\hline G3 & 5 & & \\
\hline G4 & 50.82 & & \\
\hline G5 & 50.00 & & \\
\hline G6 & 50.00 & & \\
\hline G7 & 59.98 & & \\
\hline G8 & 10 & & \\
\hline G9 & 45.18 & & \\
\hline
\end{tabular}

TABLE III. OPTIMAL GENERATION SCHEDUE WITH TCSC

\begin{tabular}{|c|c|c|c|c|c|}
\hline $\begin{array}{l}\text { Gen } \\
\text { No. }\end{array}$ & $\begin{array}{c}\text { Generation } \\
\text { schedule } \\
\text { (MW) }\end{array}$ & $\begin{array}{c}\text { Social } \\
\text { welfare }\end{array}$ & $\begin{array}{c}\text { Total } \\
\text { Generation } \\
\text { cost }(\$ / h)\end{array}$ & $\begin{array}{c}\text { TCSC } \\
\text { location }\end{array}$ & $\begin{array}{c}\text { Compensation } \\
\text { value (p.u.) }\end{array}$ \\
\hline G1 & 10 & \multirow{9}{*}{8000.50} & \multirow{9}{*}{6224.530} & \multirow{9}{*}{ Line 1-2 } & \multirow{9}{*}{$60.13 \%$} \\
\hline $\mathrm{G} 2$ & 5 & & & & \\
\hline G3 & 5 & & & & \\
\hline G4 & 10 & & & & \\
\hline G5 & 50.00 & & & & \\
\hline G6 & 50.00 & & & & \\
\hline G7 & 83.71 & & & & \\
\hline G8 & 17.14 & & & & \\
\hline G9 & 55.57 & & & & \\
\hline
\end{tabular}




\section{CONCLUSION}

In this paper an algorithm for congestion management based on OPF framework and using TCSC has been proposed. It is solved with the objective function of maximizing the social welfare by using GA for optimal fine-tuning generation and loads schedule and locationsizing of one unit TCSC.

The proposed method was tested on IEEE 30-bus system and validated through comparison of obtained social welfare with and without TCSC. Above method only tested on IEEE 30-bus system although it can be extended to any practical network.

\section{REFERENCES}

[1] Naresh Acharya and N. Mithulananthan, "Locating series FACTS devices for congestion management in deregulated electricity markets," Electric Power Systems Research, vol. 77, pp. 352-360, March 2007.

[2] Nadarajah Mithulananthan and Naresh Acharya, "A proposal for investment recovery of FACTS devices in deregulated electricity markets," Electric Power Systems Research, vol. 77, pp. 695-703, April 2007.

[3] P. L. Jaskow and J. Tirole, "Transmission rights and market power on electric power networks," in RAND J. Econ. 31, Autumn 2000, pp. 450-487.

[4] R. S. Fang and A. K. David, "Transmission congestion management in electricity market," IEEE Transactions on Power Systems, vol. 14, No. 3, pp. 887-883, August 1999.

[5] A. K. David, "Dispatch methodologies for open access transmission systems," IEEE Transactions on Power Systems, vol. 13, No. 1, pp. 46-53, Feb. 1998.

[6] S. N. Singh and A. K. David, "A new approach for placement of FACTS devices in open power markets," IEEE Power Engineering Review 21, pp. 58-60, Sep. 2001.
International Journal of Computer Applications (0975 - 8887)

Volume 6-No.6, September 2010

[7] Yog. Raj Sood, "Evolutionary programming based optimal power flow and its validation for deregulated power system analysis," Electric Power Systems Research, vol. 29, pp. 65-75, March 2006.

[8] G. B. Shrestha and Wang Feng, "Effects of series compensation on spot price power markets," Electric Power Systems Research, vol. 27, pp. 428-436, March 2005.

[9] S.N. Singh and A. K. David, "Optimal location of FACTS devices for congestion management," Electric Power Systems Research, vol. 58, pp. 71-79, Oct. 2000.

[10] M, Shiddehpour, H. Yamin and Z.Y. LI, 2002. Market Operations in Electric Power System. New York: Wiley, pp. 477-478,

[11] V. C. Ramesh and X. Li, "A Fuzzy multiobjective approach to contingency constrained OPF," IEEE Transaction on Power System, vol. 12, No. 3, pp. 1348-1354, 1997.

\section{APPENDIX}

Table A1. Cost coefficient data for generators and loads of the IEEE 30-bus test system.

\begin{tabular}{|c|c|c|c|c|c|c|}
\hline \multicolumn{2}{|c|}{ Bus no. } & $\mathrm{a}$ & $\mathrm{b}$ & $\mathrm{c}$ & $\mathrm{P}_{\min }$ & $\mathrm{P}_{\max }$ \\
\hline G1 & 30 & 0.024 & 49.327 & 187.364 & 10.00 & 20.00 \\
\hline G2 & 24 & 0.016 & 39.889 & 128.820 & 5.00 & 20.00 \\
\hline G3 & 11 & 0.014 & 37.889 & 118.820 & 5.00 & 20.00 \\
\hline G4 & 2 & 0.006 & 18.100 & 218.335 & 10.00 & 80.00 \\
\hline G5 & 8 & 0.009 & 13.353 & 81.298 & 10.00 & 50.00 \\
\hline G6 & 5 & 0.009 & 13.327 & 81.136 & 10.00 & 50.00 \\
\hline G7 & 1 & 0.005 & 10.694 & 142.734 & 20.00 & 100.00 \\
\hline G8 & 13 & 0.010 & 19.327 & 287.136 & 10.00 & 70.00 \\
\hline G9 & 15 & 0.007 & 18.300 & 230.000 & 10.00 & 60.00 \\
\hline
\end{tabular}

